\title{
Heritage image-making
}

\section{How digital documentation makes the artefact in ethnographic museum collecting}

\author{
GEOFFREY GOWLLAND
}

\begin{abstract}
This article reflects on the relationships between artefacts newly collected by ethnographic museums and the digital images that illustrate such artefacts in museum archives and catalogues. Taking three examples derived from collecting activities and ethnographic fieldwork in China and Taiwan, the article reflects on the potential of images to not simply "contextualise" artefacts, but to shape the relationships that are established between museums, the makers of artefacts, and the related source communities. More specifically, through three cases it is discussed how images can: 1) come to position makers within a tradition, 2) offer solutions to issues of rights over designs, and 3) link the collected artefact to the land from which materials were gathered. In the concluding discussion, four aspects of "images of collecting" are discussed: their materiality, their role in the creation of value, risks of misinterpretation, and responsibilities involved in editing and selecting images.
\end{abstract}

Keywords: Collecting, ethnographic museums, photography, video, Taiwan, China.

In this article, I present some thoughts on the relationship between newly collected ethnographic artefacts and the images that accompany them to the museum based on my own experiences of collecting artefacts in two different settings, in China and in Taiwan, for two ethnographic museums, the Museum of Archaeology and Anthropology of the University of Cambridge and the Cultural History Museum of the University of Oslo. As part of these collecting activities, I produced images - still and video - that are related to the artefacts. These images have accompanied the artefacts to the museum, as a video presentation contextualising the artefacts in an exhibition or as material for the museum catalogue and archives.

Much has been written about historical ethnographic collections and the conditions of collecting, including the relationship between museums and source communities (e.g. Tythacott \& Arvanitis 2014). There has been far less reflection on the documentation process specifically related to collecting, either historically or in contemporary collecting. Documentation of collecting might include 
filming and documenting the process of making the commissioned artefacts, the moment of preparation of the materials, contextualising the artefact by showing it in use, and the casual images of handing over the artefacts to collectors. This might be because, at first glance, little seems to distinguish images meant for a museum from other images that are part of ethnographic practices and fieldwork. Such images seem to operate as documentation that "merely" contextualises the artefacts and does not have the significance of the artefacts themselves. Yet in producing such images in connection to collecting, and specifically commissioning artefacts, I have become aware of elements that have led me to perceive them as particular kinds of images. This is because they have, as I will argue in this article, a particularly complex relation to the artefacts, makers, collectors, and museums, which merits closer attention.

Images of collecting are arguably becoming increasinglycomplex, and new sets ofissuesarise in the particular times in which we are living and in the interconnection of (as I see it) three phenomena. The first is increased awareness of the relationships between museums and source communities and the expressed need for museums to modify practices based on this awareness, as discussed in anthropology and museum studies (e.g. Peers \& Brown 2005). The second is the growing accessibility of image-taking technology (digital cameras and smartphones), and the third, which is related to the second, is an increased awareness on the part of the people we interact with in the field of the power of images. These three phenomena combine to create new and creative acts of documentation that accompany artefacts. Crucially, the authorship of images of ethnographic collecting is becoming blurred, even in cases in which the ethnographer is in charge of handling the camera and editing the footage. Artefact producers and informants influence and direct our image-making (Rasmussen 2015).

The three cases I briefly discuss here are not meant to serve as models or best practices but rather to point to aspects of image-making practices that can easily be overlooked and that can bring us to cast a second glance at other images present in museum archives. I will argue that such images, rather than passively providing a backdrop or "context" for a better appreciation of the artefacts, can carry the agency of those represented and are generative of new relationships between artefacts and people and between communities and museums.

The theoretical point of departure of the ideas developed in this article comes from a series of articles by Marilyn Strathern (1990, $1992,1993)$ that directly and indirectly address issues of visual anthropology. In these writings, Strathern asks what we can learn from looking at images, whether those captured by a camera or those created in the mind's eye of witnesses to ceremonial displays. She distinguishes between two different conceptions of what an image is and it's relation to history; images can act as witnesses to events, where events are understood as chance and historical circumstantial occurrences in time, but the events and images capturing these events can also be performative (1990:29), that is, they are not just the recording of context and history leading up to an event but bring about a state of affairs, reconfiguring existing relationships among attendants to the display, and are to be evaluated by the effects they have on audiences (those who participate in the performance). In other words, images may contain events and do not need to be explained with reference to historical context. The power of images 


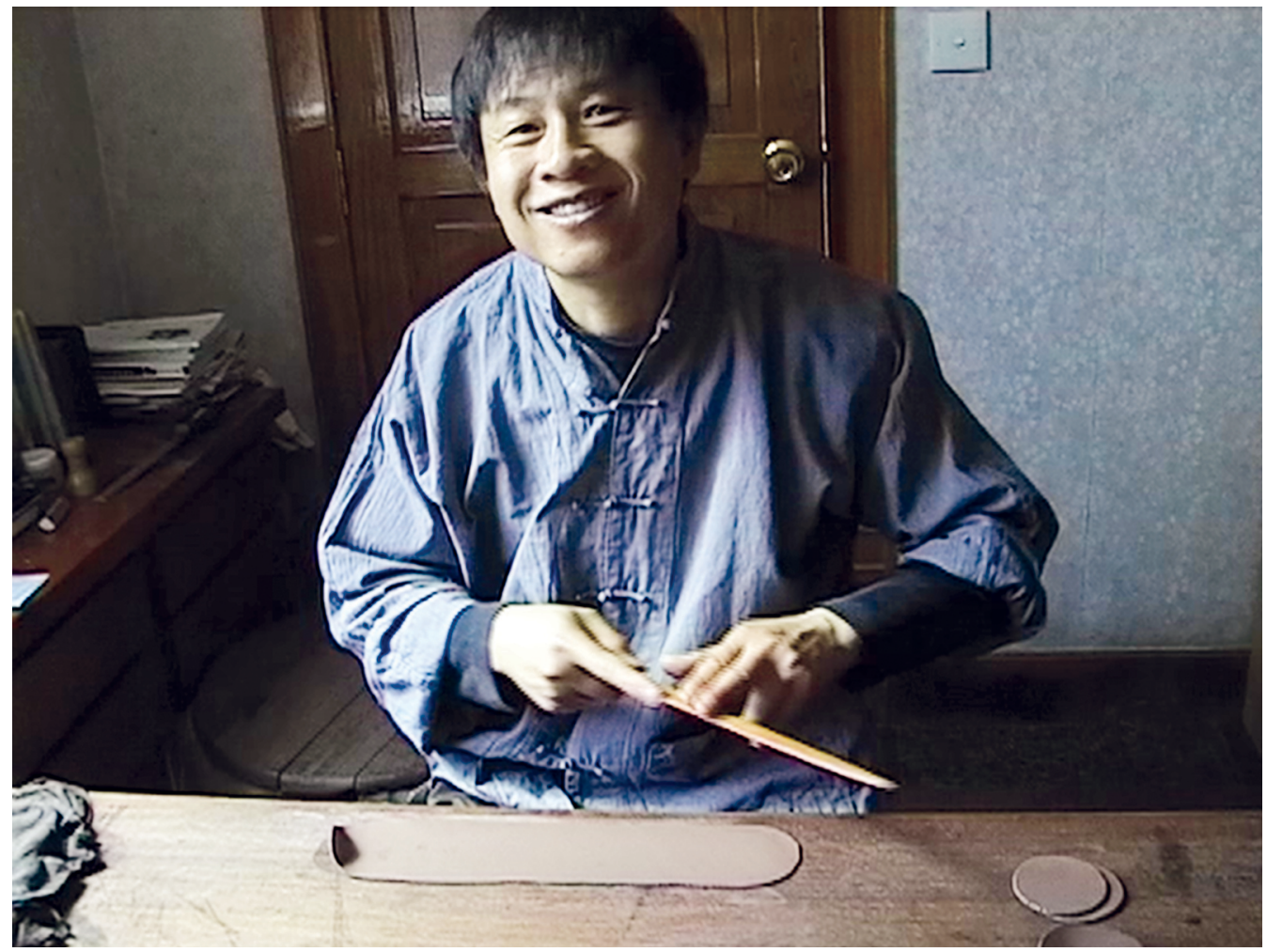

Fig. 1. Video still of artisan Ge Taozhong at work. Photo by Geoffrey Gowlland.

to create social reality, rather than simply to reflect it, is echoed in later writings in visual anthropology, significantly, in debates over indigenous media (Turner 1992; Boyer 2006). What I take from these arguments is that it can be important to consider how images do not simply provide context to events but can be generative of the effects of such events. Events and the images that capture them effectively are creative of new social realities. Thus, I suggest that what I identify as "images of collecting" create relationships, specifically between materials, artefacts, makers, traditions, communities, and museums to shape artefacts into significant and valuable items of heritage.
The three illustrative cases I detail here come from my field research and collecting activities in China and Taiwan. This means that the images of collecting I discuss are also images of ethnographic fieldwork, and knowledge of the field provides the elements that allow me to analyse the images. In the first, I explore how a film of an artisan making a ceramic pot in China has shaped the value of the depicted artefact and helped position the artisan within a tradition. The relationship with tradition is also the topic of the second example, in which I consider how an artisan from the Paiwan people of Taiwan has grappled with the different demands of 
the community and of the collecting museum, and how images have solved a major problem for him. In the third, which also addresses a Paiwan artisan and artist, I look to the material relations that link the collected artefact to the place where art materials are gathered, and how images make this relationship material. In concluding the discussion, I highlight four points to consider in relation to images of collecting: their materiality, creation of value, risk of misinterpretation, and implications of ethnographers (in collaboration with image subjects) taking the role of editors of images.

\section{REVEALING CRAFTWORK}

I start with a still from a video (fig. 1) from my doctoral research in 2003-2004 in China's selfidentified "Capital of Pottery" on a particular tradition of pottery, the zisha "purple clay" pottery of the Jiangsu province, which is an essential component of the tea ceremonies in many parts of China. As part of my fieldwork, I was a recipient of a grant from the Cambridge Museum of Archaeology and Anthropology (MAA) to collect and exhibit artefacts from the field. I was particularly interested in the unique techniques of production of these pots, which few people outside the area in which they are produced would be familiar with. In this respect, it was important for me to document the making of a pot from start to finish - a process that can take several days. Therefore, when I commissioned a pot from master Ge Taozhong, I also asked to document the process of making the pot, to which he happily agreed. The images filmed and edited from close to six hours of footage to about 20 minutes of video became a key part of the semipermanent display of the artefacts (alongside production tools) in a glass case at the MAA. The video transformed the display of items of
Chinese ceramics into a display of ingenuity, technique, and skill, giving a glimpse into the origins of the artefacts on display. The artefact one sees being made in the images is the same that was collected (fig. 2).

I have previously written about what images of craft reveal about craftwork (Gowlland 2015a) and have discussed this particular video (Gowlland 2015b, 2017:12-13, 119). Here, I want to extend this discussion to the context of collection and the role images play in collecting and accessioning the artefact. In my previous writings I reflected on the paradox of images of craftwork that both seem to reveal and mystify. They reveal because they bring us "behind the scenes" and let us see how an object is produced, but they mystify because, in the end, we are kept at a distance from full understanding of the making of artefacts with skill. In the still from the video, master Ge Taozhong looks up at me (behind the camera) after performing a simple yet clever procedure involving unsticking a piece of clay from the work table using a flat bamboo tool.

Fig. 2. Ge Taozhong's finished pot "Shui Ping Hu". Artefact in the collections of the Cambridge Museum of Archaeology and Anthropology, accession number 2004.183. Photo Geoffrey Gowlland.

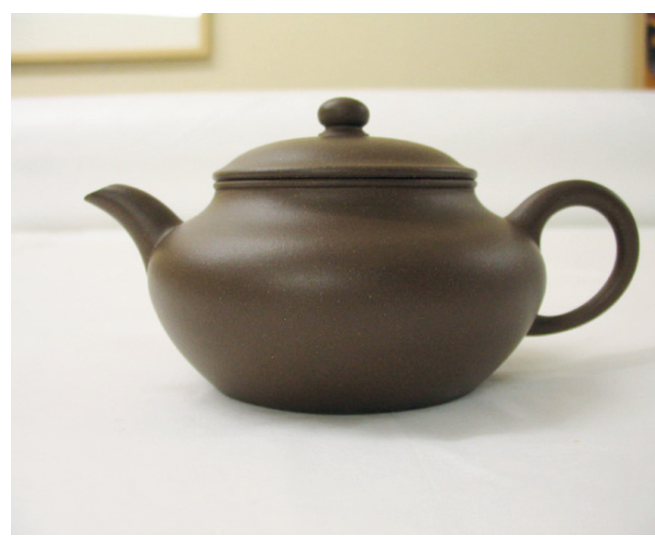


In the image, master Ge flashes a rare smile, reminding me of a magician revealing a trick.

This image captures a moment of connection between the image-taker and image subject. Only on a few occasions does $\mathrm{Ge}$ seem to acknowledge my presence in the video footage. In some of these moments, he actually tries to hide it from the camera, while trying to get me to understand that something interesting is about to happen with subtle gestures and without lifting his eyes from his work. This demonstrates an important dimension of the video, that, although I am behind the camera and would eventually be in charge of editing the video, Master $\mathrm{Ge}$ is creating the mise-enscène; he is performing, both to make a craft object and as character in a film. Perhaps most revealing, after just a few minutes of filming, Ge indicated that he had forgotten something, left the room and returned with the shirt he is wearing in the film, which is more Chineselooking than the plain blue jumper he was wearing. Thus, he is crafting his own image at the same time as he is crafting the pot.

His self-awareness is present in the video, and therefore, of all the still images I might have chosen out of six hours of footage, this is the one that is most relevant to me for the purpose of this article. He looks up at the camera. This is a break in the authenticity of the images and a break from the "observational" genre of ethnographic film making (see Grimshaw 2001), which I intended to produce by witnessing the work of an artisan going about his usual practice. The moments of selfawareness then make the images different than the simple documentation of the making of a piece of craft. They subtly reveal the relationship between the ethnographer and maker. They also reveal a more complex relationship than that observed at first glance. $\mathrm{Ge}$ is directing the images being observed, rather than simply giving his work practice to be observed. In other words, they hint at the agency of $\mathrm{Ge}$ in producing the video, subtly shaping the image of himself that appears on tape and pointing to his ideas about what the images can potentially be.

The artefact shown in the video is the actual artefact I collected for the museum, which creates a further complex relationship between images of an artefact being made and the artefact itself. One of the final moments of production of the artefact shown in the video is of $\mathrm{Ge}$ inscribing the base of the pot, marking it as a donation to the University of Cambridge Museum. The link between the maker and product is inscribed into the clay (Gowlland 2017:125-42), but this inscription is also etched onto the video representation of the clay. Artisans producing zisha pots take pains to enhance their fame and associate an artefact with a maker. This has long been done by inscribing the pot with the name of its maker. A more recent approach, though a bit outmoded today, consists in selling artefacts with a certificate containing a photograph of the maker holding the pot. The video I discuss here acted as a similar kind of imagemaking technique that could create a strong bond between Ge and his product, as a way of indicating authenticity of provenance. However, for Ge, it was also a way to link him with techniques that are traditional. Ge claimed that he was one of very few to still use many of the techniques of the past that have been replaced with modern tools. The video then becomes a document linking $\mathrm{Ge}$ with "tradition". In the images, for instance, he uses a tool, a hand-made wooden disc that has been supplanted by the modern metal turntable. Ge knew that these images would eventually circulate online, and beyond the interest of having them shown in a museum, 


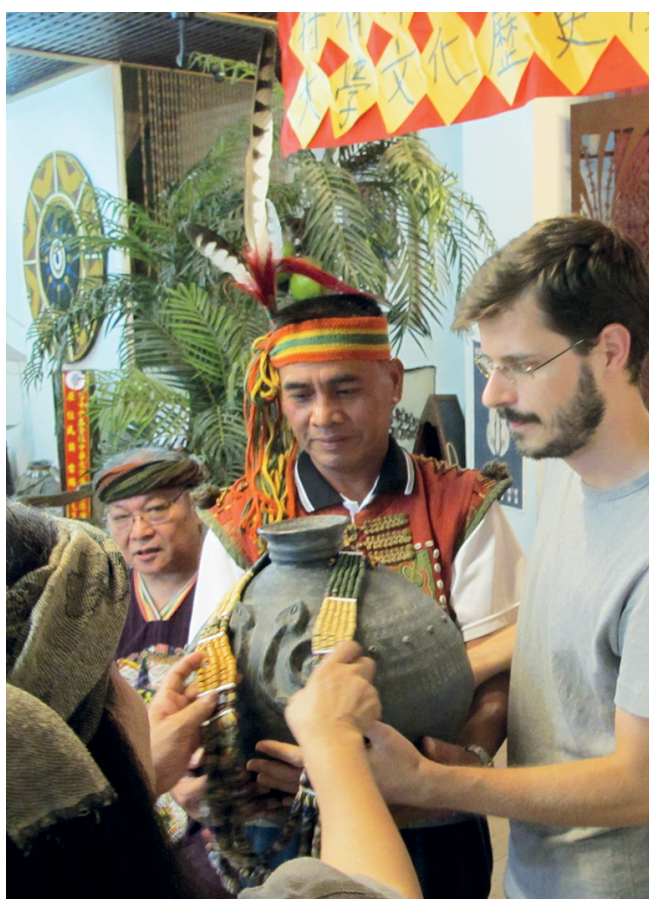

Fig. 3. The ethnographer and Paiwan chieftain holding together two artefacts, a reretan pot decorated with a glass bead necklace; in the background, artisan Umass Zingrur observes the proceedings. Photo Geoffrey Gowlland.

he was also interested in the possibility of pointing potential purchasers of his work to the video posted online. This was a time before the widespread availability of digital cameras, and $\mathrm{Ge}$ did not have one himself. On a return visit, younger practitioners talked about how useful the video had been, as a unique access to the work of a master. The film I produced was perhaps the first, and still one of few, to document the process from start to finish over several days.

In the museum, these images have the potential to affect the encounter that the audiences have with the artefact; more than an object of contemplation, they are a "witness" (Thiemeyer 2015) to the labour and skills shown in the video. The images are more than the documentation of a process, they also transform what the object comes to stand for in the museum. One might think of the images as an intervention into the fabric of relations that is established with the collecting of an artefact. My intention in providing images of making in the museum display was to shape how museum goers appreciate artefacts on display, as products of skilled practice rather than merely as objects of contemplation. Ge was also intervening in the web of relations, creating his own mise-en-scène, presenting himself as representative of the crafting tradition.

\section{HERITAGE RELATIONSHIP-MAKING}

My next example concerns a photograph (fig. 3) illustrating the transfer of an artefact to the Cultural History Museum (KHM) in Oslo.

In 2013, my wife Marzia Varutti and I received a grant from KHM to collect artefacts from the indigenous people of Taiwan (there are now 17 recognised indigenous peoples in Taiwan; here, I focus on the Paiwan people). Our idea was to create a collection of what I think of as "heritage objects" (Clifford 2004). These are artefacts produced for the main purpose of recreating objects of heritage, rather than for instance use or ritual value. In Taiwan, revitalisation of craft and art practices have sustained many political claims to cultural resilience and recognition of indigenous status (Varutti 2015). Umass Zingrur (seen in the background of the picture) might be considered the father of this craft revitalisation movement, as he was one of the first - if not the first - to revive a tradition specifically as "heritage". He is known as the person who 
revived the glass bead manufacturing of the Paiwan. Without going into detail, it is worth noting that this is a curious revival since glass beads that are treasures for the Paiwan were likely originally acquired through trade, rather than made by the Paiwan themselves, and Umass was probably the first Paiwan person in history to make glass ${ }^{1}$ beads.

When I approached Umass with the commissioning request, he insisted that I collect not only glass bead artefacts (fig. 4) but also two other artefacts, a decorated ceramic pot and a bronze knife. These would be made by his two sons. The suggestion made sense since all three types of artefacts are of high significance for the Paiwan and are collectively referred to as the "three treasures" of the Paiwan. Umass wanted to provide to a museum in Europe a collection that was complete in representing these three treasures. This needs some qualification; rather than three cultural treasures, these are the treasures of particular Paiwan families, the mamazangilan, often translated as "chieftains" in the anthropological literature. Paiwan society is made up of two kinds of people, the people of the earth and people of the sun; the mamazangilan are the descendants of the daughter of the sun, though they can lose their status through intermarriage. Chieftain families have certain rights to names, house names, and the use of certain designs in decorating their persons or houses. Artefacts with representations of the sun for instance can only be used by chieftains, and the bronze knife was in the past an artefact reserved for the chieftains for ritual purposes.

This background on Paiwan society and material culture is important for my discussion because questions of rights to designs presented Umass with an issue that needed to be resolved for him to create artefacts for the museum. Umass is not mamazangilan, but his wife

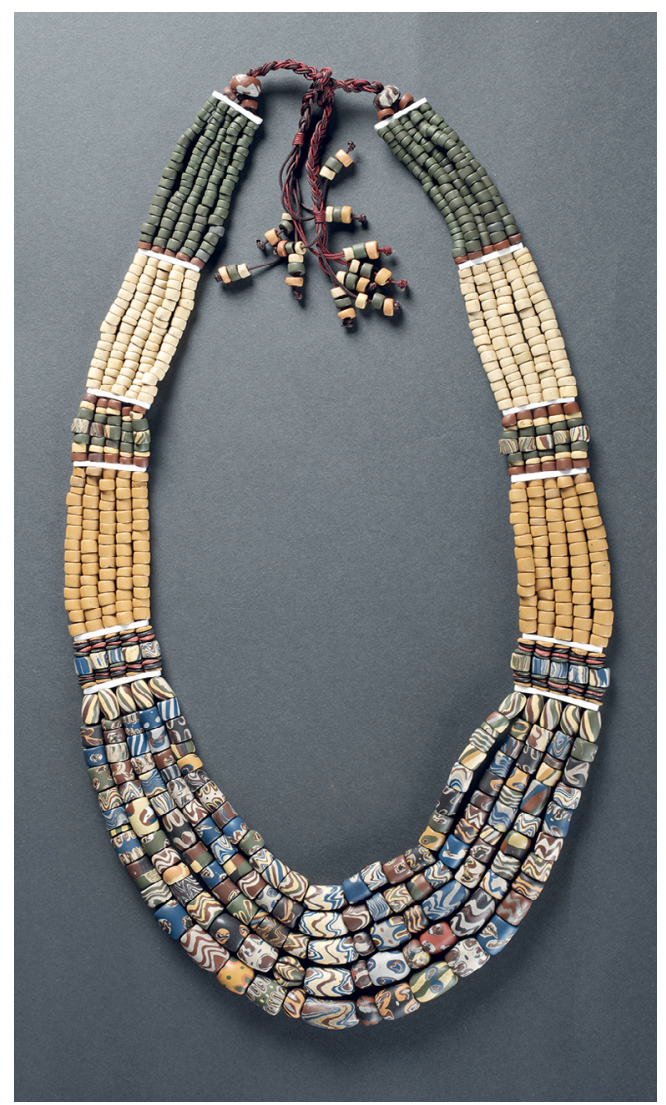

Fig. 4. Chieftain glass bead necklace by Umass Zingrur. Artefact in the collections of the Cultural History Museum in Oslo, accession number UEM49471. Photo Kirsten Jensen Helgeland.

is, and so are his sons (because they are the offspring of one mamazangilan parent). At the same time, Umass is presenting himself as a person who is in a unique position to create with the help of members of his family all three treasures of the mamazangilan. It is not an issue for him to create artefacts of reserved use by mamazangilan, as long as the request is made by a mamazangilan. However, in this case he had received a request from a 
52 Norwegian museum. He could have produced commoner artefacts, but this did not fit with his plan of providing all three Paiwan treasures that would represent the Paiwan people in a Norwegian museum.

Paiwan artisans and artists are confronted with similar issues all the time. They produce artefacts for sale to Paiwan and non-Paiwan people alike, and glass beads are notably sold all over Taiwan as jewellery. What happens when restricted designs are up for sale? One of my main interlocutors, a Paiwan artist, once characterised the situation he and fellow artists and artisans encountered as "selling taboo" using the Paiwan word palisi meaning the laws that regulate behaviour, including the rights to use and display certain designs. The perceived problem is not so much that cultural artefacts are being introduced into the market economy and sold to non-Paiwan people, but that artists who might have certain rights over the designs, for instance if they are mamazangilan themselves, are taking the liberty to sell these designs to Paiwan people who do not have such rights. Paiwan purchasers in turn claim that because they bought the artefacts from those who have the rights to the designs, they are justified to use and display them.

Umass wanted to transfer mamazangilan artefacts to a foreign museum, but he needed to address this "selling taboo" issue. His solution was fairly straightforward. He arranged for the artefacts to be handed over, not by himself, but by a member of the most important mamazangilan family who, in effect, took the decision to allow passing on the mamazangilan artefacts to KHM. This legitimised the transfer of otherwise restricted artefacts to a museum far from the Paiwan world. This is arguably also what made the artefacts "heritage", as the artefacts were extracted from the circle of rights and regulations restricting designs to become representative of the Paiwan people in a distant museum.

Images were significant in this transfer of artefacts. When we agreed on a date to pick up the artefacts, Umass insisted that we should take part in a gathering to celebrate the transfer. On the day, we met with a halfdozen individuals, all of whom turned out to be mamazangilan. Not only were photographs taken during the ceremony organised by Umass, but the ceremony seems to have been staged for photographs (my camera was one of several used by different individuals present to take the same images from different angles). For instance, the mamazangilan person who transferred the artefacts to me came in wearing ordinary clothing but was given Paiwan clothing for the photographs. We posed for the cameras, staying still, looking in turn into the lenses of the different cameras that were pointed at us. In the background, a banner announcing the event, prepared by Umass's wife and workshop workers earlier that day, announced that this was a ceremony for the transfer of the Paiwan three treasures to the museum of Oslo. This was used as backdrop to the staging of pictures and was captured in the images including the one shown here.

The images are thus not just contextual to the artefact, and they do not just highlight the relationship between maker and artefact (as in my first case). They are essential to the possibility of collecting the artefact in the first place, and in addition, to creating the body of artefacts as "three treasures" because they highlight or even arguably create the relationship with the mamazangilan, who alone can decide on how the designs embodied in the artefacts can be used. We often think of artefacts as being finished once the maker stops working on them, but they might continue to be formed through ritual and ceremony (see 
Venkatesan 2015; Rasmussen 2015). Digital images capturing such events can be agentive in creating new relationships between artefacts and people (c.f. Ngata et al. 2012).

\section{MATERIALISING HeRITAgE}

The third case comes from the same collection of artefacts in Taiwan. It also concerns an artefact from the Paiwan people, though from a different settlement (and the main field site during my research at Rinari/Dashi, Pingtung county). I have been in awe of the wood carvings of artist Cemelesai (Esai) Takivalit since the first time I saw them in 2011. When I knew that I had some budget to constitute a collection, two years later, I immediately thought of approaching him with a request to produce a carving for KHM's collections. What I did not quite realise at the time is how knowledgeable Esai is about his culture and people, and he would soon become one of my main interlocutors in my ethnographic research. I was thrilled when he accepted my request to produce a wood carving to be collected by the museum. I did not give any specific directives, except one of size (it had to be relatively easily transported to Oslo). His immediate reaction was to interpret this request as a carving that would represent the Paiwan in Norway and that would establish a bridge between the two countries. He soon decided to carve the representation of one of the key Paiwan myths. The completed carving shows two mythical brothers who come across a mysterious clay pot in the mountains. According to the myth, after nine months, the pot would give birth to the daughter of the sun (and ancestor of the mamazangilan). I should add a quick note that Esai avoided his own "selling taboo" issue in the choice of the myth he represented in the carving. He has rights over representations of the myth, given that one of the characters represented in the carving is his direct ancestor.

A day after Esai accepted my request, he came to find me, asking if the carving could be made of a combination of slate and wood (the slate would be carved with the wood acting as a stand). The ensuing conversations about the significance of slate for the Paiwan would change my research and made me much more attentive to this material. I was already aware of some of the uses of slate for the Paiwan. Slate is a significant material of the Paiwan and the neighbouring Rukai, and their slate houses are iconic. They have long been an object of fascination by colonial powers, evidenced for instance by reconstructions of slate houses in city parks in the Japanese era and, more recently, by the inclusion of several slate houses in Taiwan's national Indigenous Park. However, Esai would further point out the many culturally significant uses of slate in the past for tombs, terracing fields, building dry walls, seating inside and outside houses, and drying vegetables in the sun - and the combination of slate with wood. He pointed out the complementarity of the two materials and how a slate house cannot be built without wooden beams. Yet few slate houses are still being built outside of tourist attractions, as they are being replaced with concrete buildings.

Esai's resulting carving has cultural and heritage significance for the Paiwan for the myth it represents. However, it is also a heritage object for the materials it uses, the combination of wood and slate. For this reason, Esai felt it was necessary to show me and have me document the collection and preparation of the slate to be used in the carving. For the purpose of this article, I am interested in the few minutes of video footage and photographs (fig. 5) that I collected 
54 documenting the preparation of the slate. The fact that Esai himself suggested documenting slate preparation shows how, in this case, the images were also directed to some significant extent by the maker, despite the anthropologist actually holding the camera.

The images of slate preparation give a new dimension to the collected artefact. It can induce one to see beyond the surface of carved designs and beyond what is represented to appreciate the material of the artefact, its materiality, and the origins of the materials in the mountains of Taiwan. We get a sense of the lives of materials (Ingold 2007) and their trajectories and histories before they become a cultural artefact. In the video footage, we see Esai looking around the river bed for a suitable piece of slate. The Paiwan distinguish between male and female slate depending on the relative strength or softness of the material, and within this basic two-fold division, they name different qualities of strength or softness. Esai needed to find a slate that would be of the ideal softness to be carved. After Esai finds an interesting slab of slate, he prepares it by slicing it lengthwise to obtain two thinner slabs, using metal plates that he hammers into the sides of the slate slab until it separates into two sheets.

In the images we see the place where slate comes from, and we can appreciate the connection between a "cultural" artefact and the "natural" world. However, nature and culture are not separate in such a way; the Paiwan live in a landscape that includes the settlement and is shaped by the forces of ancestors and the mountains. Before travelling to the river bed, Esai had explained other things about this particular area. River beds are often considered palisi, a word translated as "taboo" in the academic literature. This is the same term referred to above, in the case of Umass. The Paiwan are Austronesian people, and

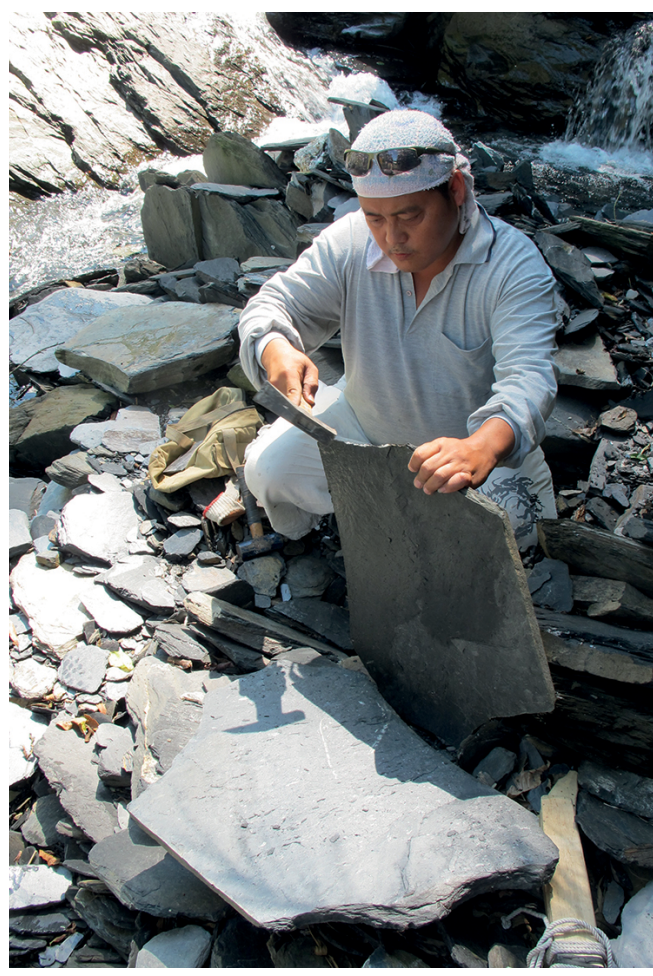

Fig. 5. Cemelesai Takivalit preparing a piece of slate in preparation for carving. Photo Geoffrey Gowlland.

although not strictly correct, it is not entirely out of place to use a word from the Pacific, "taboo", as a translation for palisi. Many areas of the mountains and in human settlements are considered palisi, which implies that they call for respect and adequate behaviours on the part of passers-by. For some areas, this means that one should avoid them entirely. For other palisi areas, one should make an offering when approaching or simply act respectfully and not make loud noises or rash movements. Before reaching the riverbed shown in these images, Esai had explained that, in the past, it was inhabited by a dangerous red-eyed spirit. Slate thus does not simply come from "nature", but 
from specific places where powerful and often dangerous forces are at play.

When Esai finished preparing the slate, as shown in the video footage, he spent a long time looking around for one of his tools. I helped search around the one spot where he had been working, but it was nowhere to be seen. He soon abandoned the search, and we went back to his car when he explained that we should not have looked too attentively for it and that perhaps it had been taken in exchange for the slate we had just taken from that riverbed.

The video shows where the artefact comes from, it highlights, reinforces, or recreates a link between a cultural, carved object and the natural place it comes from. However, we can also see the mountains and the river bed where the slate comes from in the way that a Paiwan might perceive it, as places that are not just "nature" in general but are made up of particular areas that one comes to know for the resources they offer but also by the phenomena or dangers associated with them. Although not explicit in the footage because, when talking to the camera, Esai is talking in technical terms about slate preparation, the video connects the artefact with the forces of the mountains, the earthquakes that loosen rocks, the torrential rains that precipitate them into riverbeds, and the spiritual forces that animate these places. More than a connection to a source community, the artefact might well be an object of exchange with the spirits of the mountains. Images that accompany the piece enforce the connection and can bring those curious about the artefact to look beyond the carved and meaningful surface to the life of the material from which it is made.

The artefact (fig. 6) was much heavier than the small wooden carving I originally planned to bring back. Nonetheless, the weight of the material is significant. It is a piece of the mountains that are the ancestral lands of the Paiwan. The metal tool, last seen in the filmed images, might have been the necessary exchange item for a piece of material to be brought from a palisi area to a distant land. The video image, lighter to carry back, connects the Paiwan to Oslo and connects the forces that animate the Taiwanese mountains to an ethnographic museum.

\section{CONClusion: Digital-MATERIAL RELATIONS}

A lot more could be said on each case, but hopefully, the quick sketch about three individual snapshots and their relationship to artefacts and to people can support my point that "images of collecting" are more than just images of collecting. I would make four general remarks about my discussion of the images above and across cases to start sketching what we could think of as a theory of such "images of collecting".

First, the fact that these images accompany material artefacts might make us more attentive to the materiality of digital images. I suggest that we need to think of images of collecting as artefacts themselves, albeit particular kinds of artefacts. Their digital nature does not make them "immaterial" insofar as they need computer hardware to exist. Nevertheless, they are certainly not material in the same sense as the artefacts. We might say that their materiality is relational (Hui 2012) because they literally exist as relations between bits, between 0 s and $1 \mathrm{~s}$ stored electronically in hardware in distributed locations. They can travel not as "stuff" but as relations, and as they travel, they can accrue a biography (Kopytoff 1986). Materially, they are thus ontologically different from the artefacts they accompany 


\section{GEOFFREY GOWLLAND}

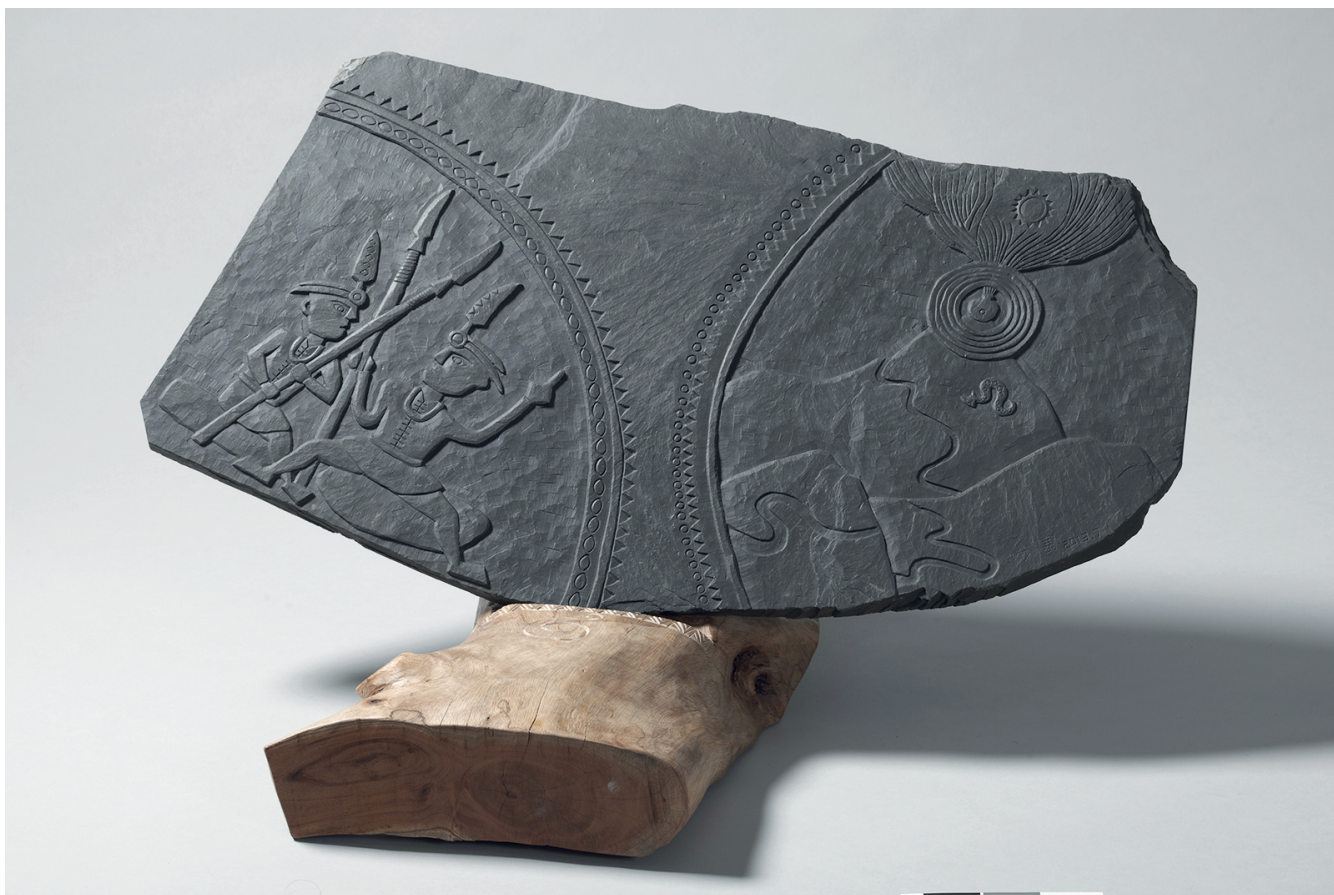

Fig. 6. Slate carving on wooden stand by Cemelesai Takivalit. Artefact in the collections of the Cultural History Museum in Oslo, accession number UEM49468. Photo Kirsten Jensen Helgeland.

but are not "immaterial". Digital images are relational in other ways. In museum catalogues, they relate to other digital objects, be it descriptions of artefacts or catalogue entries and categories. These establish a relationship between the digital materials of catalogues and the materials of artefacts. However, we have seen also that digital images are particularly powerful in establishing relations between things and people (Ngata et al. 2012). Artefacts might have a strong relationship to a people or individuals; yet, this relation might be unstable. Museums might miscategorise an artefact, or as in the past, curators might not think that it needs attribution to an individual maker. An image has the power of juxtaposition (Thomas 2010), of creating relations between images of people and images of things the pot and its maker in the first case I discussed, the pot and particular Paiwan families in the second, and a piece of slate and the spirits of the mountains in the third.

My second point concerns the role of museums in creating value. It is perhaps safe to say that ethnographic museum collections increasingly involve the commissioning of artefacts. This is in part a recognition that, even though contemporary artisans and artists from source communities might be producing very different artefacts from those of the past, they are ensuring a certain continuity of material cultural practices. It also is an ethical response to issues relating to the collections of the past, issued from unequal relations 
of power between colonising museums and colonised people (Brown \& Peers 2005). In the many "art worlds" (Becker 1982, Myers 2002) of indigenous arts worldwide, museums play a non-negligible role, influencing through commissioning and collecting the value of art and crafts items (Varutti 2015). Just as in contemporary art, where the artist needs the art critic to gain recognition and to provide an interpretation of the works that will serve to shape the value of the material objects produced, the anthropological museum creates value by providing a context to artefacts, at times giving a voice to source communities in interpreting them. For artists, having artefacts in the collections of museums plays a role in their own fame-building activities.

My third point concerns the risks of misinterpretation. Through documentation, we are making knowledge about the artefact and the "context" of this artefact accessible. This "context material" interacts with the "contextualised" (the artefacts) in more complex ways than are first evident. As part of the contextualisation efforts of museums, images are noteworthy. Unlike text, images leave room for multiple interpretations (Edwards 1997, Pink 2007). Museums tend to dislike over-interpretation. For example, text is kept at a minimum in museum catalogues (as opposed to lengthy academic articles) and even more so as labels in museum exhibitions (curators tend to assume that visitors have dreadfully short attention spans). Images are open interpretation and, in that respect, have a particular affinity to artefacts, which are also open to interpretation. This openness can represent a risk for the maker, namely having the artefacts misunderstood. Images such as the ones discussed above can be considered actions on the part of the artists or artisans on this risk of misrecognition or misinterpretation. Makers are self-aware of their image being carried with the artefacts. They also appear to have thought about the potential power of images. Increasingly, the people we collect artefacts from are themselves producers of images, made possible by the increased availability of image-capturing devices and platforms - notably Facebook - for their distribution. Although the ethnographer is the person with the illusory power of editing, informants and makers are skilled editors of what is given to the camera lens to capture, that is, what is given to see to imagined future audiences. In this respect, images take on a different status than contextualising devices. They are the agency of the maker in shaping what the artefacts are. As in the second of my cases, it appears that, in creating a ceremony that could be captured on digital sensors (I almost wrote "on film"), Umass transformed objects of traditional power into heritage objects, extracting them from the rights of specific families to allow them to become part of the collections of a foreign museum.

My fourth point concerns the power of editing. As producers of images, anthropologists and museum professionals edit images. This involves literal editing in the case of video footage. I have previously (Gowlland 2015b) discussed some aspects of editing of the first images I discuss here and some specific challenges that I encountered in editing a film showing craft processes (and necessarily leaving out crucial aspects of skilled practice for the benefit of viewer comprehension). However, still images are also edited, if only by selecting those deemed representative and discarding the ones that are not. Editing is a process of exclusion, removing what we think is not necessary to show, to get to the essence of what we think is important to show. In the three sets of images I have discussed here, there is a blurred and not immediately 
apparent sharing of the editing work. I am not the only editor of images, all three makers the potter Ge Taozhong, bead-maker Umass Zingrur, and carver Cemelesai Takivalit - are also acting as editors (Gowlland 2017:143-65). In their own way, they have selected what is to be framed, shown, and concealed from view. Makers are editing in a different way, by selecting and discarding aspects of their work to reveal other aspects, for instance revealing relationships contained but invisible in the artefact (Strathern 1992) - relationships with a tradition, with a people, with specific families, and with museums. They are also editors of their culture - pointing to what is important to know and to be seen. One might give a thought to what and who might be absent from these edited works. First, perhaps those artists and artisans who were not given a chance by the museum collector to have their work collected and to have their own chance at shaping how their people are represented in a museum.

There have never been so many images of heritage. There have never been so many images and so many possibilities to capture, store, and process them and to create associations with other images and digital objects. There have never before been so many creators of images. The images we take in the field might have already been taken by tourists or by our informants themselves or may have been posted on YouTube and shared via Facebook. For these reasons, images of collecting might seem relatively unremarkable, as there might be little that distinguishes them from the images produced by others. Nonetheless, this is what makes them remarkable; they are images that we might not think twice about yet convey the agency of the persons represented in them to shape at a distance both the artefacts and how audiences might encounter them. This remarkable unremarkableness might lead us to revisit images, including the images in ethnographic museum archives taken by explorers and collectors of the past, to reflect not on what is represented in them but what kind of objects these images are, what kind of performances they contain, what the effects of these performances are, and what has been left or edited out of them.

\section{Notes}

1. These are actually not or are no longer made of glass but use a ceramic formula developed by Umass.

\section{REFERENCES}

Becker, Howard S. 1982. Art Worlds. Berkeley: University of California Press.

Boyer, Dominic. 2006. “Turner's anthropology of media and its legacies." Critique of Anthropology 26:1, 47-60. DOI: 10.1177/0308275X06061483

Clifford, James. 2004. “Looking several ways: Anthropology and native heritage in Alaska." Current Anthropology 45:1,5-30. DOI: $10.1086 / 379634$

Edwards, Elizabeth. 1997. "Beyond the boundary: A consideration of the expressive in photography and anthropology." In Howard Morphy \& Marcus Banks (eds.) Rethinking Visual Anthropology. New Haven, CT: Yale University Press, 53-80.

Gowlland, Geoffrey 2015a. "Imaging/imagining craftwork." Visual Anthropology 28:4, 267-276. DOI: 10.1080/08949468.2015.1052305

Gowlland, Geoffrey 2015b. "Unpacking craft skills: What can images reveal about the embodied experience of craft?" Visual Anthropology 28:4, 286-297. DOI: 10.1080/08949468.2015.1052324

Gowlland, Geoffrey 2017. Reinventing Craft in China: The Contemporary Politics of Yixing Zisha Ceramics. Wantage: Sean Kingston Publishing. 
Grimshaw, Anna 2001. The Ethnographers Eye: Ways of Seeing in Anthropology. Cambridge: Cambridge University Press.

Hui, Yuk 2012. "What is a digital object?" Metaphilosophy 43:4, 380-95. DOI: 10.1111/j.1467-9973.2012.01761.x

Ingold, Tim 2007. "Materials against materiality." Archaeological Dialogues 14:1, 1-16. DOI: 10.1017/S1380203807002127

Kopytoff, Igor 1986. “The cultural biography of things: Commoditization as process." In Arjun Appadurai (ed.) The Social Life of Things: Commodities in Cultural Perspective. Cambridge: Cambridge University Press, 64-91.

Myers, Fred 2002. Painting Culture: The Making of an Aboriginal High Art. Durham, NC: Duke University Press.

Ngata, Wayne, Hera Ngata-Gibson, and Amiria Salmond 2012. “Te Ataakura: Digital Taonga and cultural innovation." Journal of Material Culture 17:3, 229-244. DOI: 10.1177/1359183512453807

Peers, Laura \& Alison Brown, 2003. Museums and Source Communities: A Routledge reader. London: Routledge.

Pink, Sarah 2007. Doing Visual Ethnography: Images, Media and Representation in Research. London: Sage.

Rasmussen, Anders Emil 2015. "Images as things: Photographing and filming kastom in Papua New Guinea." Visual Anthropology 28:4, 336-350. DOI: 10.1080/08949468.2015.1052325

Strathern, Marilyn 1990. "Artefacts of history: Events and the interpretation of images." In Jukka Siikala (ed.) Culture and History in the Pacific. Helsinki: Transactions of the Finnish Anthropological Society, 25-44.

Strathern, Marilyn 1992. "The decomposition of an event." Cultural Anthropology 7:2, 244-254.
Strathern, Marilyn 1993. “One-legged gender.” Visual Anthropology Review 9:1, 42-51. DOI: 10.1525/ var.1993.9.1.42

Thiemeyer, Thomas 2015. "Work, specimen, witness: How different perspectives on museum objects alter the way they are perceived and the values attributed to them." Museum and Society 13:3, 396-412.

Thomas, Nicholas 2010. “The museum as method." Museum Anthropology 33:1, 6-10. DOI: 10.1111/j.1548-1379.2010.01070.x

Turner, Terence 1992. "Defiant images: The Kayapo appropriation of video." Anthropology Today 8:6, 5-16. DOI: $10.2307 / 2783265$

Tythacott, Louise and Kostas Arvanitis 2014. Museums and restitution: New practices, new approaches. Farnham: Ashgate.

Varutti, Marzia 2015. "Crafting heritage: Artisans and the making of indigenous heritage in contemporary Taiwan”. International Journal of Heritage Studies 21:10, 1036-49. DOI: $10.1080 / 13527258.2015 .1050055$

Venkatesan, Soumhya 2015. "After the event: Video and its potential for uncovering information." Visual Anthropology 28:4, 298-307. DOI: $10.1080 / 08949468.2015 .1052326$

Geoffrey Gowlland, Ph.D., Honorary Research Fellow

geoffrey.gowlland@khm.uio.no

Cultural History Museum

University of Oslo

P.O. Box 6762

St. Olavs plass

N-0130 Oslo Norway 